\title{
Study on the Historical Change of the Production Mode and the Its Development Trend
}

\section{Liu Qichun}

The Institute of Marxism of Hubei University of Chinese Medicine, Wuhan City, Hubei Province, zip code 430065, China

liuqichunwu@126.com

Keywords: production mode; historical change; development trend

\begin{abstract}
The mode of production refers to the way of obtaining material resources necessary for social life. During the continuous development of human society, the mode of production is constantly changing. This is a manifestation of the progress of science and technology, and is also a manifestation of social development towards a more advanced level. The productive forces are closely related to the relationship between production and production, and a unified whole is formed directly with social conditions and economic relations. In the current society, the mode of production has begun to develop towards globalization, intellectualization, virtualization and information. It is of theoretical and practical significance to analyze the historical transformation and development trend of the whole production mode. Based on the definition of production mode, this paper first analyzes the historical transformation of production mode, and then studies the development trend of production mode, hoping to provide some reference for related research.
\end{abstract}

\section{Definition of the mode of production}

The mode of production is the definition of political economics, and it refers to a form of human acquisition of necessary material in social life. As the middle part of the productive forces and relations of production "mode of production", and change with the development of production tools and production technology, directly reflects the level of development and the nature of productive forces; at the same time, the mode of production is closely related to the relations of production, production is restricted by the social conditions and economic relations. The mode of production includes the material exchange relationship between man and nature, the material exchange between labor and labor and the social change relationship between people's occupation of labor. In the labor due to different material elements, so the combination of labor and the results are different, different labor may use different tools, process of nature or life data, so that the mode of production is the relationship between man and nature is a pure. Of course, when the transformation relationship between labor elements and social material is combined in a specific way, labor and labor can achieve the transformation of material. At the same time, the mode of production reflects the relationship between natural and social forces. In some labor, due to the contradiction between individual labor and social labor, the ownership of labor may change, reflecting the content of labor wealth and the social relationship between people.

\section{Historical changes in the mode of production}

The change of production mode directly promotes the progress of human civilization. In the long history of history, the transformation of production mode is mainly divided into three stages. These three stages make nature evolve towards the society and to the advanced direction. Of course, in the process of transformation of the mode of production, a civilization has been formed, and the quality of people's life has been greatly improved. From the perspective of historical development, the historical changes in the specific mode of production are as follows. 


\subsection{Manual and single piece production mode}

In the stone age, human beings mainly live on the basis of natural tools, using natural tools. At the time of bronze and iron age, people began forging, mining and metallurgy. They began to build various tools independently, and made all kinds of simpler machines, forming an agricultural economy and producing them in families. At this stage, the mode of production is still human, but the part has begun to use wind and water power. Compared to the stone age, this is a great progress of human civilization. To the middle of eighteenth Century, the emergence of the steam engine ushered in the industrial revolution, human beings get rid of the traditional manpower and animal power constraints, to obtain a more powerful production. At this time, the production of family style began to change to industrial production, greatly improving the efficiency of production. However, the industrial production is still at the level of single piece production, and its basic characteristics are as follows:

(1) the product is relatively low end and rough. At that time, most of the production and processing according to customer demand for customized, manually operated machine has no unified standards of measurement, product quality of output is determined by the individual operation ability, affected by subjective factors more, so many products can meet the requirements of general specifications, the consistency and reliability of get effective protection.

(2) low production efficiency. At that time, the ability of science and technology to be converted into productivity was limited and production efficiency was low.

(3) the production skills are mainly based on internal learning. At that time, social skills such as machine processing, product design and assembly were mostly started from apprenticeship, and they studied hard in continuous production, so as to accumulate relevant experience.

(4) the relationship between production and management is relatively simple. At that time, the production and organization level of the factory was very simple, and the internal management was looser. The relationship of production management only included cooperation, employees and customers. Although the difficulty and cost of management are reduced to a certain extent, it is not conducive to the improvement of production efficiency and the control of the quality of production.

\subsection{Mass production mode}

One of the great changes in the manufacturing industry in the history of human history is the transformation from single production to mass production, which strongly promotes the process of industrialization. On the one hand, the quality of people's life has been improved effectively. On the other hand, the market economy has been promoted in the global scope. In this process, people's product design and processing have begun to be managed with a unified standard, so it is more professional and systematic. At the same time, using assembly line and special equipment to assist processing, effectively improve the efficiency of production, plus a unified system, make the whole plant's internal management more perfect, and improve the quality of products. At this stage, the cost of production has declined, the quality and productivity of products have been improved effectively, and the cycle of production has also been greatly reduced. Therefore, the appearance of industrial production has undergone tremendous changes, and productivity has increased rapidly, which has accumulated a lot of social wealth.

\subsection{Flexible automatic production}

In the middle of last century, people realize that the rigid production line, the labor division of labor too small, leads to functional disorder, but also for production of a single product, a lot of poor adaptability of equipment and pipeline, not according to the market demand for change. With the bureaucracy of the organizational structure, the cost of the management of the production organization has been greatly improved. In order to solve this problem, the production began to seek new ways to improve the efficiency of industrial production and its adaptability. The hallmark of the change of production mode is the emergence of computers in the United States, and the introduction of computers into the production field. Automation is controlled by some programs, and flexible 
production is adopted to solve the problem of product adaptability. This stage of production has been automated, production efficiency and processing effect are good, and the adaptability of the equipment is strong, and it can be changed accordingly according to the production needs. Because of the advanced production mode, the enterprise can optimize the management of its own, promote the maturity of the commodity production and improve the economic benefit of the enterprise.

In the 80s of last century, the mode of production has changed to some extent. The advanced production technology of computer and network has changed the way of production to the direction of advanced production mode.

(1) the use of computers to form an integrated system of production. The production integration system based on computer is a closed loop feedback system. After entering the product needs and corresponding concepts, we can export higher quality products and services. When the enterprise in all aspects, including the demand for the product research, design and development, manufacturing, assembly process, decision-making and management, and customer service service, to form an organic whole, can be changed according to the social needs, the more flexible, and global coordination capacity has been greatly improved. Due to the further optimization of its own management, the product production cycle is shorter, the output quality is higher, the production efficiency is higher, it can provide better service for customers, so the market competitiveness of enterprises is bigger. Coupled with the industrial technology is very mature, machinery and equipment is highly efficient use, can customize computer systems and software, etc., to achieve a modern manufacturing.

(2) concurrent engineering. Concurrent engineering is evolved with the increasing competition and social enterprise, this project is the whole work of the unified model, designers can let early in product development to take into account the operation of the latter, on time, cost and quality of the full range of control. Using this model, the cycle of production can be shortened effectively and the rate of product development can be accelerated. Due to the overall consideration of the earlier period, the corresponding changes in the subsequent production are less, which will help to save the cost of production. The close cooperation between different professions has also made a great change in the thought of production. The design of products will consider the problems of economy and environmental protection.

(3) lean production. The concept of lean production was proposed by the Massachusetts Institute of Technology in the United States. It was well absorbed by the Germans and formed an advanced mode of production. This production mode aims at simplifying the process of production and manufacturing, making rational use of time, transforming single production into mixed production, and improving the social adaptability of products by using small batch turns. At the same time, this mode requires enterprises to simplify their organization within the organization and decentralization of power, so that all production and development tasks can be carried out smoothly. More representative is that products begin to adopt modularized production structure, which can transform at different levels according to the market demand, avoid the problem of product rigidity, and make use of the machine with high automation to carry out diversified production.

\section{The development trend of the mode of production}

Combined with the historical change of production mode and the demand of current social development, the development trend of production mode is mainly reflected in the following aspects:

(1) intelligentization. The society is progressing. The level of science and technology has provided better help for people. Therefore, in the future development, the mode of production will achieve intellectualization and greatly reduce the output of manpower. This is a major performance of the progress of production, but also can effectively improve the efficiency of production, grasp the quality of production. At present, people's production is moving towards the direction of intelligent production, has achieved some intelligent production, and has achieved good results. In the future development, it is bound to continue to improve.

(2) information. Informatization is a major theme in the current era. With the maturity of computer 
technology and network technology, the production of information can effectively analyze the market demand and make the adaptability of products greatly improved. Especially the development of economic globalization has put forward higher requirements for the production, so the production mode of informatization is a future development trend, to product combined with the global market demand for production, and help the production information transfer, improve the production efficiency and to control the quality of production.

(3) virtualization. Virtual production is an advanced concept, because the current consumption of products not only to stay in the loop, but also a lot of virtual consumption, the market demand is decided in the future development, the mode of production but also towards virtual direction, such as service products and network products etc. In the field of the whole society, the theoretical system of virtual production is not perfect enough. At present, it is still in the exploratory stage, which requires people to speed up the related research steps and promote the development of virtualization production.

(4) globalization. The globalization of production has become the inevitable trend of historical development, for the promotion of economic globalization, leading to inter regional cooperation more closely, in order to reduce the production cost and improve production quality further, production must be combined, through the way to globalization in upgrading. On the one hand, the production of globalization is aimed at improving the quality of products and reducing the cost of products. On the other hand, the production of globalization is to cater to the trend of economic development. To some extent, the way of global production can also promote regional cooperation and make the economic connection more closely. So the production of globalization will grow in a relatively short time and provide more high-quality products for the society.

\section{Conclusions}

The transformation of the mode of production is a symbol of the progress of human civilization, throughout the history of the world, the mode of production will change along with the science and technology constantly breakthroughs, and each change of mode of production also marks the human productivity has been greatly improved, can effectively improve the quality of people's lives. It is based on this point, this paper focuses on the analysis of the mode of production of historical change, and then combined with the current needs of the society to analyze the future development trend, to explore the change in the direction of the future development of productivity from the intelligence, information technology, virtualization and globalization in four directions, provide a reference to the current transformation of these can be the mode of production, make the transition more directional. Because the current production has been highly developed, and to some extent, it can achieve independent control. Therefore, we should combine the historical trend and the needs of the times, change our production mode accordingly, and provide better products for the society.

\section{References}

[1] Zhou Shaodong. "Internet plus" to promote the agricultural production mode reform -- the research of [J]. China rural observation, perspective of Marx's Political Economics Based on 2016 (06): 75-85+97.

[2] Yu Jinfu. Theory of mode of production: classic paradigm and modern innovation [J]. economist, 2015, (10): 5-10.

[3] Song Chenggang. New elements of capital, relations of production change and financial innovation [D]. Ocean University of China, 2012.

[4] Shao Peijie. Research on the reform of the current stage of agricultural production in China [D]. Henan University, 2012.

[5] peak. On "mode of production" [J]. commentary on political economics, 2012,3 (02): 3-38. 
[6] Zheng Shiming. On the historical nature and development reasons of the production mode -- Also on the influence of the new technological revolution on the transformation of production mode, [J]. philosophy research, 1985, (01): 8-16. 